Peer Reviewed Paper openaccess

\title{
Effect of colony age on near infrared hyperspectral images of foodborne bacteria
}

\author{
Paul J. Williams, ${ }^{\text {a* }}$ Terri-Lee Kammies, ${ }^{b}$ Pieter A. Gouws ${ }^{c}$ and Marena Manley ${ }^{d}$ \\ Department of Food Science, Stellenbosch University, Private Bag X1, Matieland (Stellenbosch) 7602, South Africa. E-mail: pauljw@sun.ac.za \\ a(D https://orcid.org/0000-0002-6014-2049, b ${ }^{(10)}$ https://orcid.org/0000-0001-5382-8395

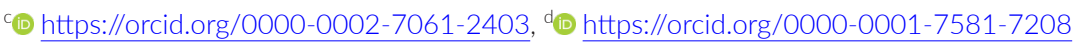

Near infrared hyperspectral imaging (NIR-HSI) and multivariate image analysis were used to distinguish between foodborne pathogenic bacteria, Bacillus cereus, Escherichia coli, Salmonella Enteritidis, Staphylococcus aureus and a non-pathogenic bacterium, Staphylococcus epidermidis. Hyperspectral images of bacteria, streaked out on Luria-Bertani agar, were acquired after $20 \mathrm{~h}, 40 \mathrm{~h}$ and $60 \mathrm{~h}$ growth at $37^{\circ} \mathrm{C}$ using a SisuCHEMA hyperspectral pushbroom imaging system with a spectral range of 920-2514nm. Three different pre-processing methods: standard normal variate (SNV), Savitzky-Golay ( $1^{\text {st }}$ derivative, $2^{\text {nd }}$ order polynomial, 15 -point smoothing) and Savitzky-Golay ( ${ }^{\text {nd }}$ derivative, $3^{\text {rd }}$ order polynomial, 15-point smoothing) were evaluated. SNV provided the most distinct clustering in the principal component score plots and was thus used as the sole pre-processing method. Partial least squares discriminant analysis (PLS-DA) models were developed for each growth period and was tested on a second set of plates, to determine the effect the age of the colony has on classification accuracies. The highest overall prediction accuracies where test plates required the least amount of growth time, was found with models built after $60 \mathrm{~h}$ growth and tested on plates after $20 \mathrm{~h}$ growth. Predictions for bacteria differentiation within these models ranged from $83.1 \%$ to $98.8 \%$ correctly predicted pixels.

Keywords: colony age, foodborne bacteria, growth media, PLS-DA, NIR hyperspectral imaging

\section{Introduction}

The widespread occurrence of foodborne diseases in developed and developing countries indicate underIying food safety flaws in adequate pathogen detection. ${ }^{1}$ Conventional methods for pathogen detection and identification are labour intensive and time consuming-often taking two to three days for initial results (enrichment and growth on specialised media) and up to a week for species identification. Pure culture identifications are typically required for regulatory and legal purposes. ${ }^{2}$ Thus, rapid methods for pathogen detection and improvements on existing methods are constantly being investigated.
Recently, near infrared (NIR) hyperspectral imaging (HSI) has been explored as a tool to differentiate pathogenic bacteria from each other as well as from non-pathogenic bacteria. ${ }^{3-6}$ Barbin et al. ${ }^{7}$ determined total viable count (TVC) and psychrotrophic plate count (PPC) on porcine meat over 21 days. Chemical changes in the meat, due to bacterial growth, were used to predict whether samples were commercially sound (those that had a bacterial count lower than $\log 6$ CFU g $^{-1}$ ). Linear discriminant analysis (LDA) models showed over $95 \%$ accuracy for spoilage detection,

\section{Correspondence}

Paul J. Williams (pauljw@sun.ac.za)

Received: 1 November 2018

Revised: 14 December 2018

Accepted: 4 January 2019

Publication: 30 January 2019

doi: $10.1255 /$ jsi.2019.a5

ISSN: $2040-4565$

\section{Citation}

P.J. Williams, T.-L. Kammies, P.A. Gouws and M. Manley, "Effect of colony age on near infrared hyperspectral images of foodborne bacteria", J. Spectral Imaging 8, a5 (2019). https://doi.org/10.1255/jsi.2019.a5 (C) 2019 The Authors

This licence permits you to use, share, copy and redistribute the paper in any medium or any format provided that a full citation to the original paper in this journal is given. 
while partial least squares (PLS) achieved coefficients of determination of 0.82 and 0.85 for TVC and PPC, respectively. In a study by Yoon et al., ${ }^{8}$ NIR hyperspectral imaging was used to facilitate the detection and identification of Campylobacter and non-Campylobacter species, using the $400-900 \mathrm{~nm}$ wavelength range. They incubated colonies for $48 \mathrm{~h}$ on three different agars (Campy-Cefex, Campy-Line and blood agar) and developed a two-step classification algorithm to differentiate Campylobacter colonies from non-Campylobacter colonies (Sphingomonas paucimobilis, Acinetobacter baumannii, Brevundimonas diminuta, Ochrobacterium sp. and Flavobacterium odoratum). Cultures grown on Cefex had the highest classification accuracies (up to $99 \%$ ). In an attempt to increase the rapidity of this method, the authors conducted a follow-up study. ${ }^{4}$ They incubated the same organisms for a shorter period ( $24 \mathrm{~h}$ ) before imaging, and compared the results to their previous study. Three different classification methods (band ratio algorithm, spectral feature fitting and single band thresholding algorithm) were applied. With the single band thresholding algorithm, the overall classification accuracy of the $48 \mathrm{~h}$ Cefex cultures (97\%) was higher than the overall $24 \mathrm{~h}$ Cefex cultures (86\%). Blood agar cultures incubated for $24 \mathrm{~h}$ showed up to $99 \%$ accuracy with the band ratio algorithm. These results demonstrated that it was possible to detect Campylobacter species using NIR-HSI after $24 \mathrm{~h}$ of growth.

When an old or damaged bacterial culture is introduced onto fresh media, the culture will undergo the normal growth phases (lag, exponential, stationary and death) in a closed system. ${ }^{9,10}$ Various genera of bacteria have different generation times and will thus not display growth phases at the same time. ${ }^{9,10}$ Furthermore, it is well known that as bacterial colonies proliferate and age on growth medium, various biochemical and physical changes occur ${ }^{11,12}$ and these, too, depend on the organism. Thus, colony age could prove to be an important factor in certain detection methods, as various metabolites could hinder detection or inhibit reagents. Coutinho et al. ${ }^{13}$ showed that colony age had a negative effect on polymerase chain reaction fingerprinting. The authors found that banding patterns were more consistent and clearer in younger (two days) than in older cultures (five days). In another study, Arnold et al. ${ }^{14}$ noted profound changes in the mass spectra of Escherichia coli strains with time. The variation was attributed to nutrient depletion, metabolite and waste accumulation and cell death. In both cases, the effect of colony age was selfexplanatory, i.e., using young cultures produce different results than older colonies, and would influence identification. To date, no studies investigated the effect of colony age on NIR hyperspectral images of bacteria. Thus, this study aims to evaluate the effect of colony age on classification of foodborne bacteria.

\section{Materials and methods Sample preparation}

Bacterial isolates of Bacillus cereus (ATCC 13061), Escherichia coli (ATCC 25922), Salmonella Enteritidis (ATCC 13076), Staphylococcus aureus (ATCC 25923) and S. epidermidis (ATCC 12228) were acquired from the culture collection of the Department of Food Science, Stellenbosch University. Two sets of streak plates were prepared for each bacterium using Luria-Bertani (LB) agar in $100 \mathrm{~mm}$ glass Petri dishes and incubated for $60 \mathrm{~h}$ at $37^{\circ} \mathrm{C}$. Streak plates were preferred as not only do they produce single colonies, but also large areas of bacterial growth where the initial streak was made. This permits the collection of more spectral data from the bacteria for analyses. LB agar was chosen because it is a common, general growth medium which contains only tryptone, yeast extract, sodium chloride and bacteriological agar powder. ${ }^{15}$ To minimise the spectral response from the growth media, only LB agar was used throughout this study. Furthermore, we decided to refrain from using selective media as these could result in the production of substances that would interfere with NIR hyperspectral imaging measurements. Plates were removed from the incubator every $20 \mathrm{~h}$, digitally imaged and then imaged with the NIR hyperspectral system. All inoculations were performed under aseptic conditions and bacterial cultures were screened for purity after NIR hyperspectral images were collected. To ensure images were not affected by the high incubation temperature, plates were left at $21^{\circ} \mathrm{C}$ for $20 \mathrm{~min}$ before imaging.

\section{NIR hyperspectral imaging system and image acquisition}

A SisuCHEMA short wave infrared camera (Specim, Spectral Imaging Ltd, Oulu, Finland) was used to acquire NIR hyperspectral images. The sensor consisted of a 2D array mercury-cadmium-telluride ( $\mathrm{HgCdTe}$ ) detector, with a light source of quartz halogen lamps as described 
in Reference 5. Once the imaging system was calibrated, images of the entire Petri dish, with the lid on to avoid contamination, were collected every $20 \mathrm{~h}$ for a period of $60 \mathrm{~h}$. These time points were chosen arbitrarily, to explore the effects of growth time on hyperspectral images, to determine if changes in culture age can be visualised and assess its effect on classification accuracies.

In total, 30 images were collected (five different bacteria, imaged at three time-intervals, in duplicate). Using streak plates allowed many single colonies to be imaged, incorporating more variation within a plate due to biochemical differences between colonies. In total (duplicate plates included), 10 images were collected. To compensate for effects of the growth media, images of Petri dishes with only agar were also acquired.

\section{Data analysis}

Individual images were imported into Evince v.2.7.0 (Prediktera AB, Umeå, Sweden) hyperspectral image analysis software package. Principal component analysis (PCA) was calculated with three components before image segmentation. This involved removing the background, agar, bad pixels and reflection from the Petri dish with the brushing technique. ${ }^{16}$ Noisy wavelengths from $920 \mathrm{~nm}$ to $1097 \mathrm{~nm}$ and $2477 \mathrm{~nm}$ to $2514 \mathrm{~nm}$ were removed and mosaics were then constructed with the cleaned images, before PCA was recalculated. To facilitate data analysis, individual images were grouped to form three mosaics, each containing a different combination of bacteria (Table 1). A mosaic was constructed for each of the growth periods, with a total of nine mosaics. This made it possible to study the bacteria and visualise differences in one image (mosaic). Similar to our previous study, $^{5}$ the bacteria were selected and grouped to include a variety of characteristics, i.e.

Gram-positive and Gram-negative pathogens

- Bacteria which appeared similar in colour on the growth media, as well as those which appeared different (to prove that colour does not affect the method)

Table 1. Grouping of bacteria for mosaic formation, used for multivariate data analysis.

\begin{tabular}{|l|l|l|}
\hline Group 1 & Group 2 & Group 3 \\
\hline B. cereus & B. cereus & S. aureus \\
\hline E. coli & S. aureus & S. epidermidis \\
\hline S. Enteritidis & S. epidermidis & \\
\hline
\end{tabular}

S. epidermidis was included to determine whether it was possible to distinguish between pathogens and non-pathogens.

However, in this study we aim to determine whether colony age would influence the ability to identify these characteristics and thus the classification accuracies. To achieve defined clustering and optimum separation in PCA score plots, thereby improving subsequent classification results, three pre-processing treatments were evaluated. We investigated SNV and Savitzky-Golay first derivative ( $2^{\text {nd }}$-order polynomial; 15 -point smoothing) and second derivative ( $3^{\text {rd }}$-order polynomial; 15 -point smoothing). Baseline correction was excluded, as this was done in combination with smoothing when SavitzkyGolay polynomial derivatives are calculated. Score plots and score images were inspected for clustering (score plots) and colour differences based on score values (score images). In the score images, warm colours (yellow to red) are indicative of high score values whereas cold colours (blue to cyan) show lower score values. A preprocessing method/combination was considered suitable when a distinct clustering of pixels for each bacterium, with minimal overlap, was observed.

The data was processed further in Matlab (The Mathworks Inc., Natick, MA, USA) and PLS_Toolbox with MIA_Toolbox 8.6.2 (Eigenvector Research, Inc., Manson, WA, USA). To determine the effect colony age has on classification, PLS-DA models were developed for each group, at each time interval and were validated independently on the duplicate plates of each time interval. The optimum number of latent variables for each model was determined using venetian blinds cross-validation with 10 splits and 20 samples per split. As too few samples were available, we decided to perform all data analyses with the pixel-wise approach. Had the object-wise approach (one image per Petri dish) been adopted, only 30 objects would be available for analysis. This was considered too few samples for classification. The data analysis process is shown in Figure 1.

\section{Results and discussion}

Digital images of each Petri dish were collected after each growth period, before hyperspectral image acquisition, using a Huawei IDEOS S7 camera (3.15 MP, $2048 \times 1536$ pixels). An example of the digital images is shown in Figure 2. 


\section{Pre-processing}

After background removal and image correction, each image comprised at least 15,000 pixels per bacteria. All calculations were done on the duplicate plates individually, yielding similar results and thus duplicate plates were deemed sufficient. When studying the PCA score plots (Figures $3 a-d$ ), it was found that SNV-pretreated data produced the best clustering for all groups over the three growth periods. Bacteria were imaged in glass Petri dishes with the lid on, when images where acquired, irregularities in the glass and reflection of the agar could have caused some scattering of light. Moreover, the elevation of all colony morphologies was raised, this slight curvature could have contributed to light scatter as well. As there were a large number of sources for possible scattering, removing it with SNV was an essential step.

Score plots and score images of groups 1 and 2 after $40 \mathrm{~h}$ growth were used as examples to illustrate the effect of pre-processing method (Figures 3-6). For group one (Figure 3), the Gram-positive B. cereus was represented by the cluster with a red centre (highest density of pixels) in each score plot (except Figure 3c), whereas Gramnegative E. coli and S. Enteritidis were represented by clusters with a yellow/cyan centre. Score plots of raw data, as well as first and second derivative pre-processed data (Figure 3a, c and d) showed either one or two clusters. Only in the score plot of SNV-transformed data, were three clusters clearly visible (Figure 3b). B. cereus was separated from E. coli and S. Enteritidis along PC 1 [30\% sum of squares (SS)] and E. coli was separated from S. Enteritidis along PC2 (11.8\% SS).

In the score image of the raw data (Figure 4a) each bacterium appears different, with varying levels of score values (positive and negative), when compared to each other. This is possibly due to scattering effects caused by varying morphology of the bacterial colonies on the growth media. In the pre-processed score images (Figure 4b, c and d), E. coli and S. Enteritidis seem similar, whereas $B$. cereus is different, signifying the presence of notable chemical variances between Gram-positive B. cereus and the two Gram-negative bacteria-E. coli and S. Enteritidis. Differences between Gram-positive and Gram-negative

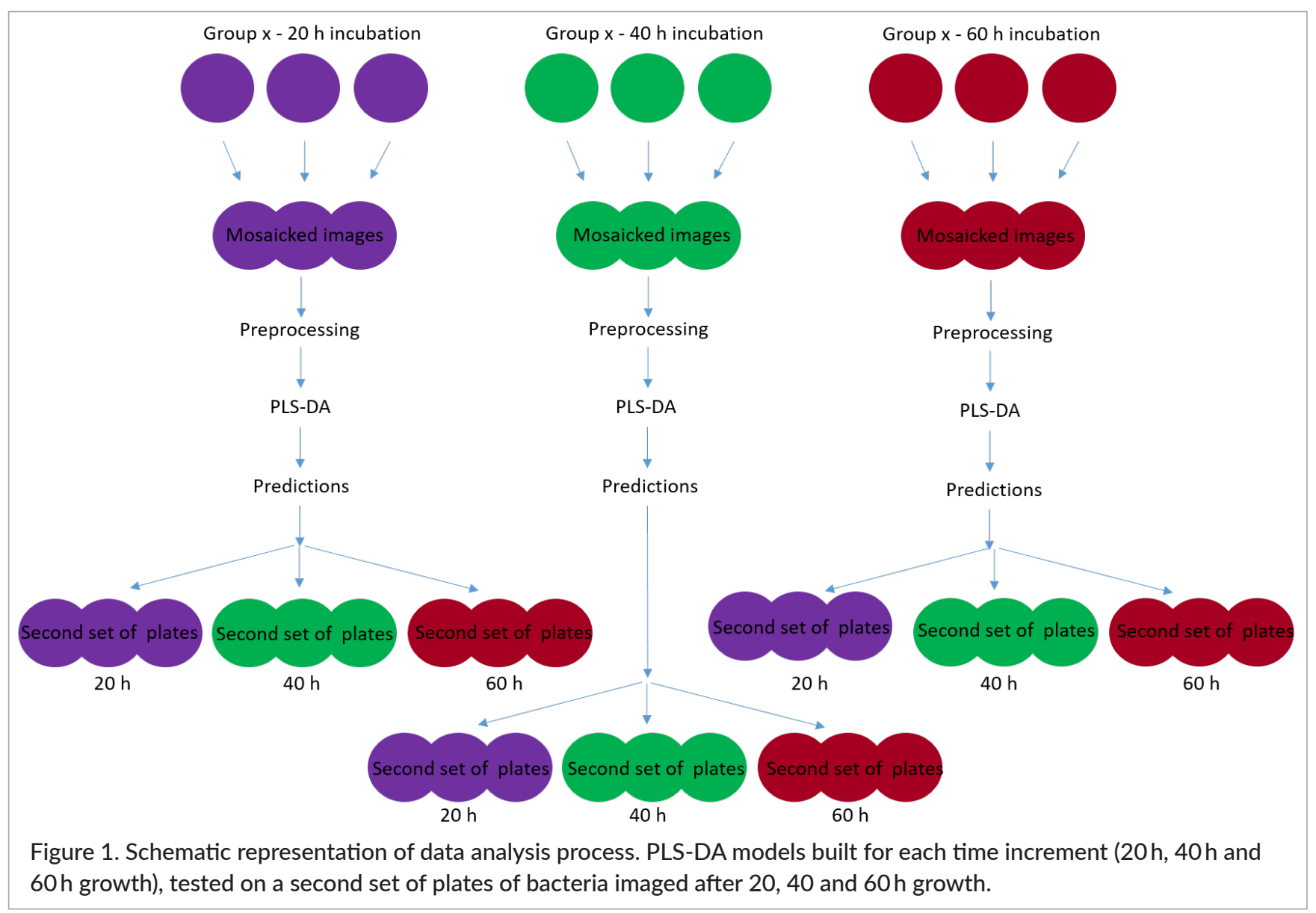


bacteria are due to distinct variation in cell wall composition. ${ }^{17-19}$ In an earlier study, Kammies et al. ${ }^{5}$ reported that differences in protein and carbohydrate structures in Gram-positive and Gram-negative bacteria, combined with the absence of teichoic acid in the cell walls of Gramnegative bacteria, were the main factors contributing to the variation observed.
For group 2, SNV-transformed data again exhibited the best clustering, where the two pathogens (B. cereus and S. aureus) were separated from nonpathogenic S. epidermidis (Figure 5b). The score image of this pre-processing method (Figure 6b) also showed the most variation in score values between the three Gram-positive bacteria. Both pathogens appeared to

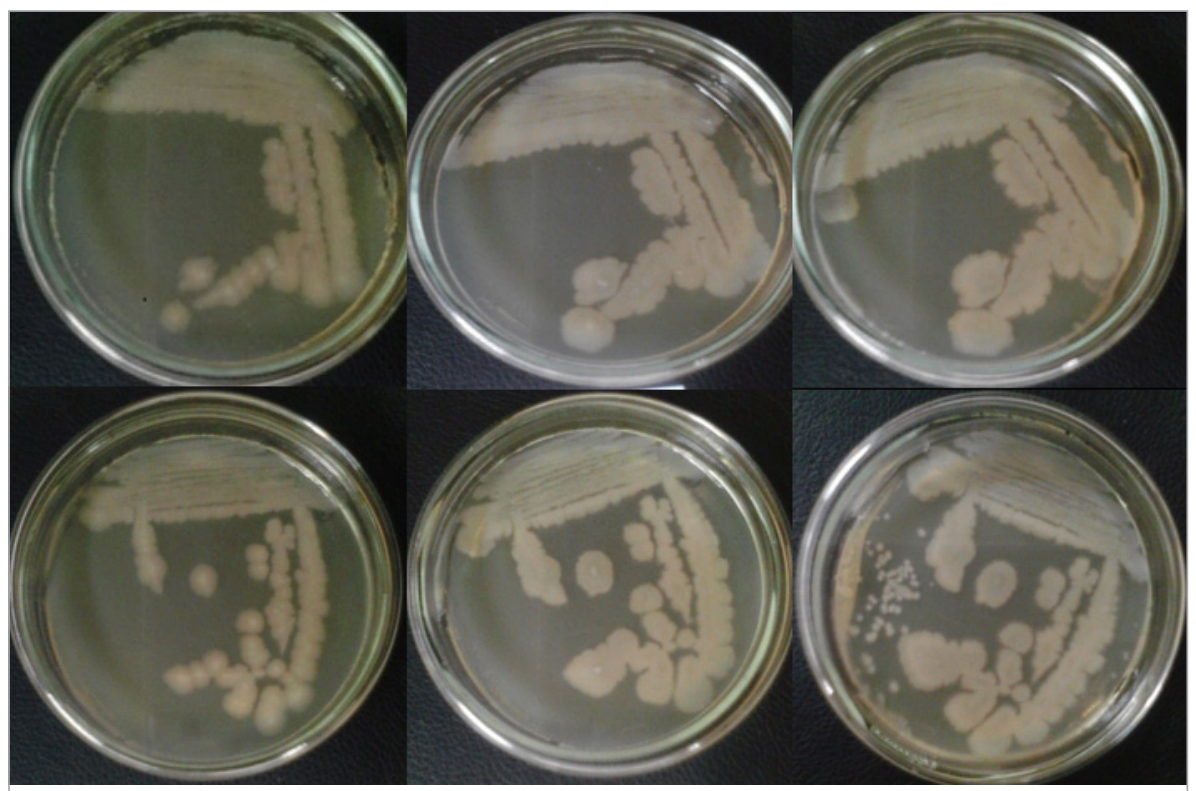

Figure 2. Digital images of $B$. cereus after $20 \mathrm{~h}, 40 \mathrm{~h}$ and $60 \mathrm{~h}$ (left to right) growth at $37^{\circ} \mathrm{C}$ with the second set of plates in the bottom row.
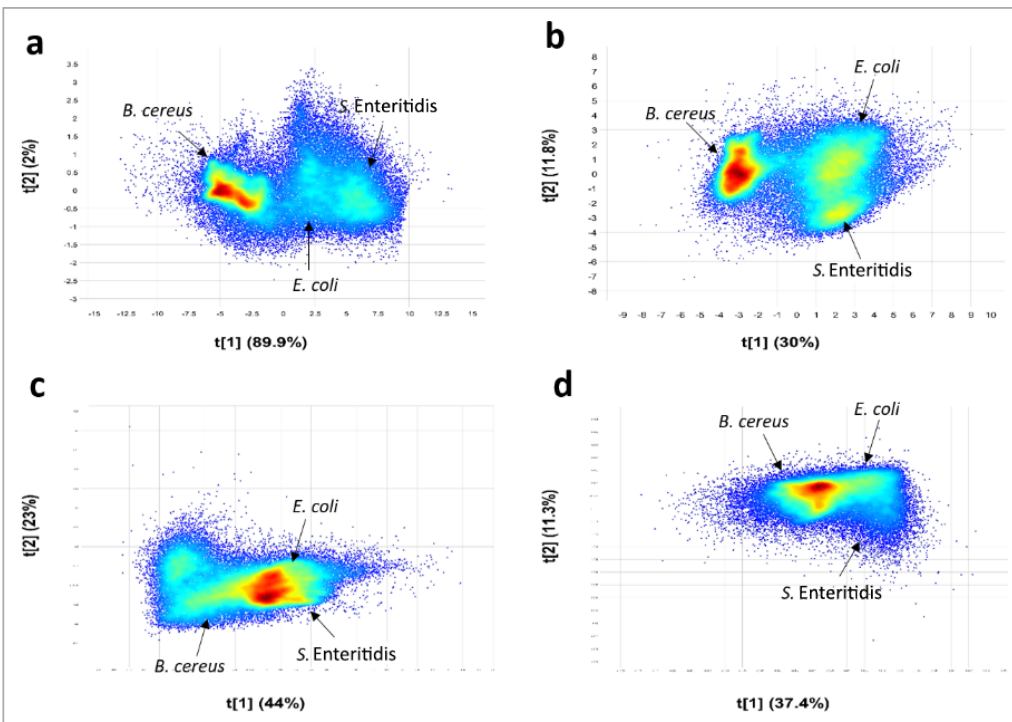

Figure 3. Score plots of PC1 vs PC2 for the mosaic of group 1 ( $B$. cereus, E. coli and S. Enteritidis) with different pre-processing methods applied. a Raw data, b SNV, c Savitzky-Golay ( $1^{\text {st }}$ derivative, $2^{\text {nd }}$ order polynomial, 15-point smoothing) and d Savitzky-Golay ( $2^{\text {nd }}$ derivative, $3^{\text {rd }}$ order polynomial, 15-point smoothing). 
have low score values, however, B. cereus was dark blue (high negative score values) while S. aureus was cyan (less negative score values). In contrast, S. epidermidis predominantly had positive score values. In the Savitzky-Golay pre-processed score images (Figure 6c and d), the two Staphylococcus species appeared very similar. These results suggest that scattering effects caused by bacteria morphology, and the other sources mentioned previously, play a major role in bacteria differentiation.
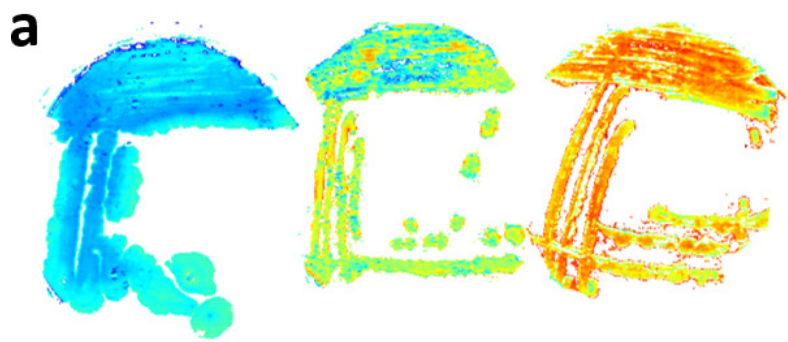

B. cereus

C

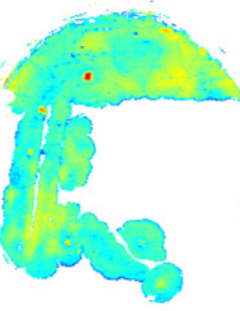

E. coli

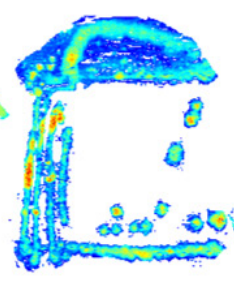

S. Enteritidis

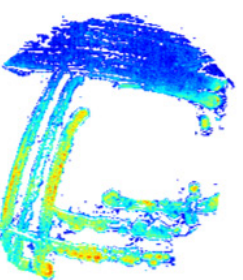

b

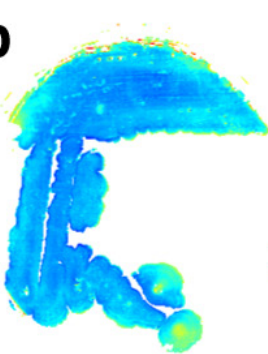

B. cereus

d

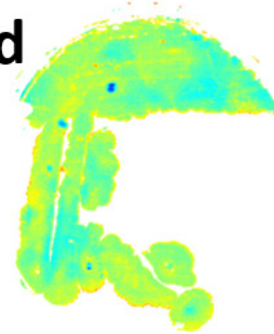

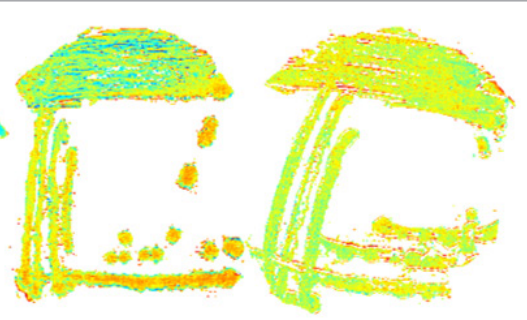

E. coli

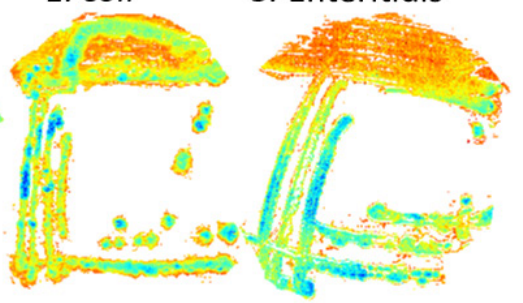

Figure 4. Score image of PC1 for the mosaic of group 1 (B. cereus, E. coli and S. Enteritidis) with different pre-processing methods applied. a Raw data, b SNV, c Savitzky-Golay ( $1^{\text {st }}$ derivative, $2^{\text {nd }}$ order polynomial, 15-point smoothing) and d Savitzky-Golay ( $2^{\text {nd }}$ derivative, $3^{\text {rd }}$ order polynomial, 15-point smoothing). Warm colours (yellow/red) are indicative of high score values and cold colours (blue/cyan) show lower score values.

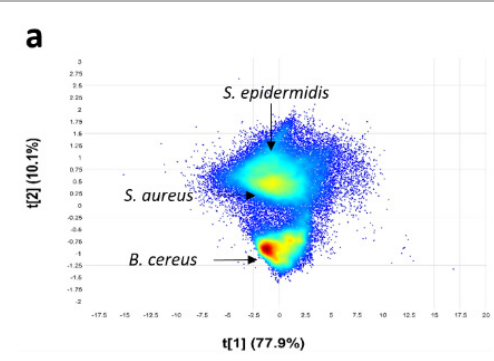

c

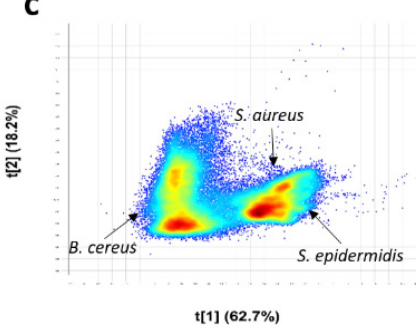

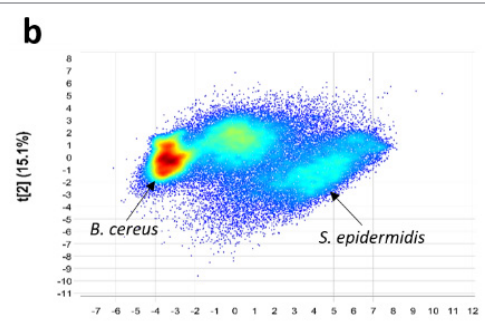

t[1] $(54 \%)$

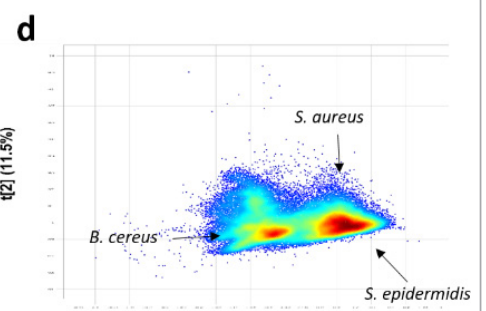

t[1] (62.5\%)

Figure 5. Score plots of PC1 vs PC2 for the mosaic of group 2

(B. cereus, S. aureus and S. epidermidis) with different pre-processing methods applied. a Raw data, b SNV, c Savitzky-Golay ( $1^{\text {st }}$ derivative, $2^{\text {nd }}$ order polynomial, 15-point smoothing) and d Savitzky-Golay ( $2^{\text {nd }}$ derivative, $3^{\text {rd }}$ order polynomial, 15-point smoothing). 


\section{Partial least squares discriminant analysis}

Results from our previous study ${ }^{5}$ indicated that it was possible to distinguish between different bacteria after $20 \mathrm{~h}$ growth, however, some classification results were not satisfactory. In order to improve classification accuracies while keeping rapidity in mind, we used older cultures (from advanced time points) to calibrate PLS-DA models and validated them on younger colonies $(20 \mathrm{~h}$ ). For example, models were calibrated on images after $60 \mathrm{~h}$ incubation and used to predict agar plates after $20 \mathrm{~h}$ growth.

The performance of the $20 \mathrm{~h}$ model for group 1 (Table 2) was good, except for the classification of B. cereus and E. coli tested on the second set of $20 \mathrm{~h}$ growth plates, where only $69 \%$ and $71 \%$ of pixels were correctly classified. As streak plates were used in this study and pixelwise classifications were done, each pixel was regarded as a colony. For this reason, these results were deemed unsatisfactory. In practice, if $30 \%$ of pathogenic colonies on a plate were not identified as such, it implies that the detection method is inadequate since a high percentage of possibly harmful contamination goes undetected. Therefore, in this study any classification accuracy under $90 \%$ correctly predicted pixels was considered low. Although a non-selective media was used that would not form part of a confirmative test, using a selective media would introduce variation that would hinder classification. Furthermore, as the proposed method aims to reduce time and costs, using a general-purpose media is appropriate.
The prediction accuracy of the model built from training data generated after $20 \mathrm{~h}$ for group 1 was nevertheless $16 \%$ higher for B. cereus than the $40 \mathrm{~h}$ model. However, for $E$. coli, this increased by $12.4 \%$. Classification results from the $60 \mathrm{~h}$ model showed an overall decrease in accuracy, except for B. cereus and E. coli after $20 \mathrm{~h}$ growth, where it increased to $97 \%$ and $83 \%$, respectively. The $R^{2}$ for the $20 \mathrm{~h}, 40 \mathrm{~h}$ and $60 \mathrm{~h}$ models were $0.45,0.57$ and 0.54 , respectively. The lowest prediction accuracies for group 1 was for B. cereus with the $20 \mathrm{~h}$ and $40 \mathrm{~h}$ models, tested with the $20 \mathrm{~h}$ growth plates (69\% and $53 \%$ correctly predicted pixels, respectively). The SNV-corrected mean spectra, of each bacterium on the respective days, were studied to obtain information about chemical compounds within each bacterium to aid in the explanation of the classification results. At $1937 \mathrm{~nm}(\mathrm{C}=\mathrm{O}$, second overtone, $\mathrm{CONH} / \mathrm{O}-\mathrm{H}$ stretch + $\mathrm{O}-\mathrm{H}$ deformation, $\mathrm{H}_{2} \mathrm{O}$, ${ }^{20}$ the spectrum of $\mathrm{B}$. cereus after $20 \mathrm{~h}$ growth (Figure 7) was closer to that of E. coli after $40 \mathrm{~h}$ growth. Whereas, after $40 \mathrm{~h}$ and $60 \mathrm{~h}$ growth the peak intensities were nearly identical across the entire wavelength range. This explains the low prediction accuracy of the $20 \mathrm{~h} \mathrm{~B}$. cereus plate for the $40 \mathrm{~h}$ model (model built from training data generated after $40 \mathrm{~h}$ ), where it might have been misclassified as E. coli. These differences are also likely due to changes in protein conformation or concentration, ${ }^{14}$ since bacterial cultures change biochemically during aging. ${ }^{11,13}$ Arnold et al. ${ }^{14}$ reported changes in the peak intensities of matrix-assisted laser desorption/ionisation mass spectra of E. coli. They ascribed the
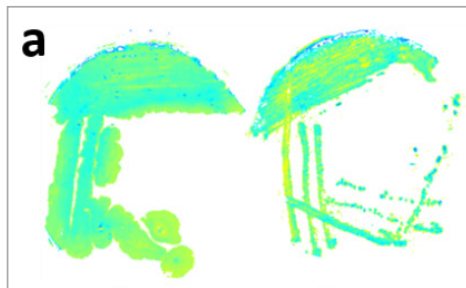

B. cereus

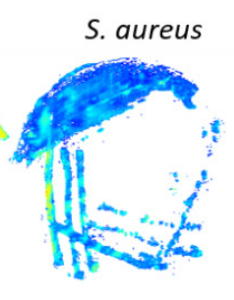

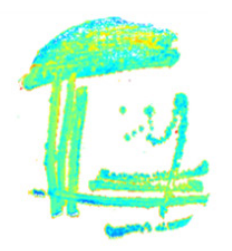
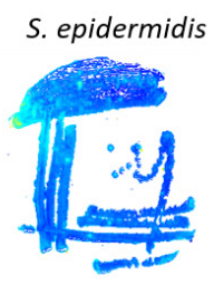

b

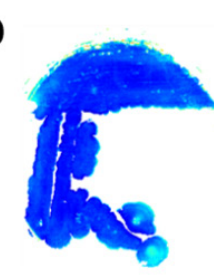

B. cereus

d

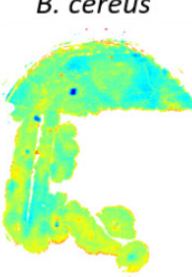

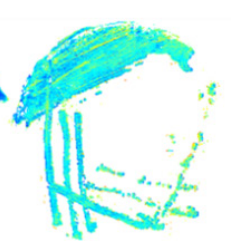

S. aureus

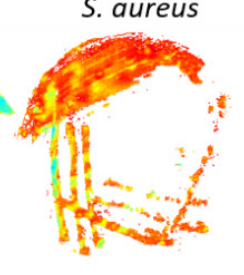

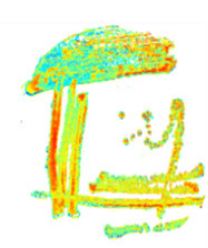

S. epidermidis

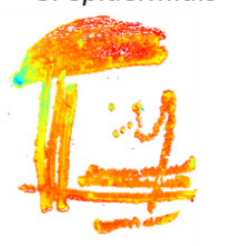

Figure 6. Score image of PC1 for the mosaic of group 2 (B. cereus, S. aureus and S. epidermidis) with different pre-processing methods applied. a Raw data, b SNV, c Savitzky-Golay $\left(1^{\text {st }}\right.$ derivative, $2^{\text {nd }}$ order polynomial, 15-point smoothing) and d Savitzky-Golay ( $2^{\text {nd }}$ derivative, $3^{\text {rd }}$ order polynomial, 15-point smoothing). Warm colours (yellow/red) are indicative of high score values and cold colours (blue/cyan) show lower score values. 
Table 2. PLS-DA results of group 1 showing classification results of $20 \mathrm{~h}, 40 \mathrm{~h}$ and $60 \mathrm{~h}$ models as percentage pixels correctly predicted.

\begin{tabular}{|c|c|c|c|}
\hline & B. cereus & E. coli & S. Enteritidis \\
\hline \multicolumn{4}{|c|}{$\begin{array}{l}\text { \% Correctly predicted pixels of validation data-model built } \\
\text { from training data generated after } 20 \mathrm{~h} \text { growth }\left(R^{2}=0.45\right)\end{array}$} \\
\hline $20 \mathrm{~h}$ growth & 69.1 & 70.6 & 90.3 \\
\hline $40 \mathrm{~h}$ growth & 99.8 & 85.9 & 96.0 \\
\hline $60 \mathrm{~h}$ growth & 96.0 & 82.4 & 87.9 \\
\hline \multicolumn{4}{|c|}{$\begin{array}{l}\text { \% Correctly predicted pixels of validation data-model built } \\
\text { from training data generated after } 40 \text { h growth }\left(R^{2}=0.57\right)\end{array}$} \\
\hline 20h growth & 53.1 & 83.0 & 81.6 \\
\hline $40 \mathrm{~h}$ growth & 95.8 & 86.5 & 95.2 \\
\hline $60 \mathrm{~h}$ growth & 92.3 & 93.1 & 89.8 \\
\hline \multicolumn{4}{|c|}{$\begin{array}{l}\text { \% Correctly predicted pixels of validation data-model built } \\
\text { from training data generated after } 60 \mathrm{~h} \text { growth }\left(R^{2}=0.54\right)\end{array}$} \\
\hline $20 \mathrm{~h}$ growth & 96.9 & 83.1 & 86.4 \\
\hline $40 \mathrm{~h}$ growth & 98.8 & 75.3 & 95.5 \\
\hline $60 \mathrm{~h}$ growth & 93.9 & 78.2 & 84.4 \\
\hline
\end{tabular}

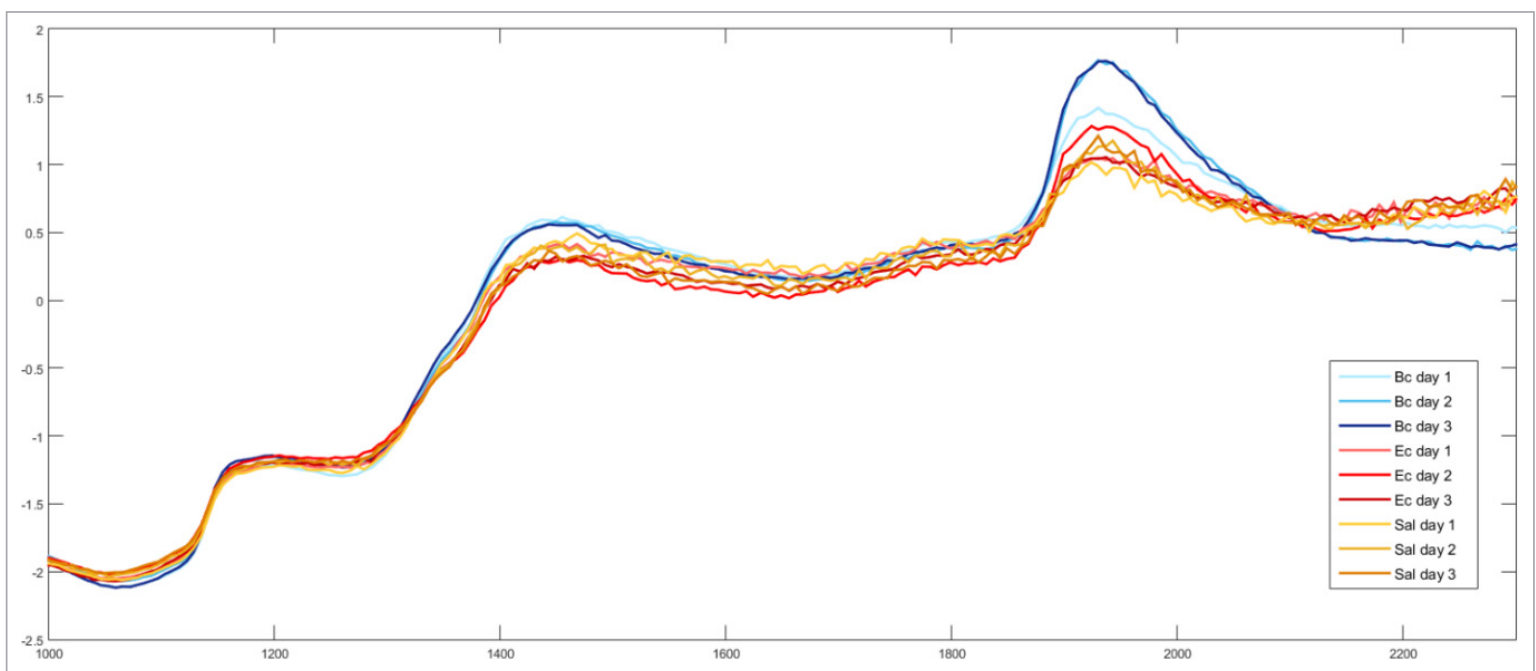

Figure 7. SNV-corrected mean spectra of group 1 [B. cereus (Bc), E. coli (Ec) and S. Enteritidis (Sal)] after 20 h, $40 \mathrm{~h}$ and $60 \mathrm{~h}$ growth, with the major peak at $1937 \mathrm{~nm}(\mathrm{C}=\mathrm{O}$, second overtone, $\mathrm{CONH} / \mathrm{O}-\mathrm{H}$ stretch $+\mathrm{O}-\mathrm{H}$ deformation, $\mathrm{H}_{2} \mathrm{O}$ ). 
peaks to ribosomal protein and noted that they changed with increasing growth time, i.e. the peaks representing ribosomal protein decreased in intensity with increasing growth time. Although they could not quantify these changes, they concluded that differences in protein were responsible for the changes in peak intensity. In the early stages of growth, bacteria proliferate rapidly and produce ribosomes for protein synthesis. With time, this requirement is reduced as growth slows. Given that the organisms in this study all exhibit different growth rates and that the same bacteria would vary on the duplicate plate, it was expected that these changes would not be consistent. Thus, the haphazard results. The approximate generation time for bacteria used in the current study is as follows: E. coli and S. Enteritidis $-20 \mathrm{~min},{ }^{21} \mathrm{~S}$. aureus and B. cereus -30 min $^{22,23}$ and S. epidermidis -45 min. $^{24}$

There was an increase in prediction accuracy for $E$. coli with the $40 \mathrm{~h}$ and $60 \mathrm{~h}$ models (models built from training data generated after $40 \mathrm{~h}$ and $60 \mathrm{~h}$, respectively), tested on the plates after $20 \mathrm{~h}$ growth. However, for the $60 \mathrm{~h}$ model, predictions of plates after $40 \mathrm{~h}$ and $60 \mathrm{~h}$ growth decreased. With the $20 \mathrm{~h}$ model as the baseline, the only increase in correctly predicted pixels for S. Enteritidis was in the $40 \mathrm{~h}$ model tested on the growth plate after $60 \mathrm{~h}$-an increase of 1.9\% (87.9-89.8\%) was observed. The best results for $B$. cereus and $S$. Enteritidis were achieved with the $20 \mathrm{~h}$ model tested on growth plates after 40 h, with $99.8 \%$ and $96.0 \%$ correctly predicted pixels, respectively. However, for $E$. coli the $60 \mathrm{~h}$ model tested on $60 \mathrm{~h}$ growth plate was the best, with $93.1 \%$ correctly predicted pixels.

For group 2 (Table 3), the $R^{2}$ for $20 \mathrm{~h}, 40 \mathrm{~h}$ and $60 \mathrm{~h}$ models were $0.80,0.75$ and 0.69 , respectively. An overall decrease in prediction accuracy was observed, except for S. aureus, where classification of pixels increased in consecutive models. The highest prediction accuracy for B. cereus was $99.9 \%$ with the $20 \mathrm{~h}$ model, predicting the $40 \mathrm{~h}$ growth plate. For both S. aureus and S. epidermidis, the $40 \mathrm{~h}$ model showed the highest prediction accuracies tested on the $20 \mathrm{~h}$ growth plates, with $97.3 \%$ and $99.3 \%$ correctly predicted pixels, respectively. In the $20 \mathrm{~h}$ and $40 \mathrm{~h}$ models, S. aureus had the lowest prediction accuracies, with only $24.6 \%$ for the $20 \mathrm{~h}$ model tested on the $60 \mathrm{~h}$ growth plate and $61.4 \%$ for the $40 \mathrm{~h}$ model, predicting the $60 \mathrm{~h}$ growth plate as well. These poor results are attributed to the slow initial growth of $S$. aureus. ${ }^{25}$ This is seen in the SNV-corrected mean spectra (Figure 8), where the intensity of the peak at $1937 \mathrm{~nm}$ $(\mathrm{C}=\mathrm{O}$, second overtone, $\mathrm{CONH} / \mathrm{O}-\mathrm{H}$ stretch $+\mathrm{O}-\mathrm{H}$ deformation, $\left.\mathrm{H}_{2} \mathrm{O}\right)^{20}$ for $\mathrm{S}$. aureus is much lower after $20 \mathrm{~h}$ growth, than $40 \mathrm{~h}$ and $60 \mathrm{~h}$ growth. This peak is likely related to protein or moisture, which are key components in all bacterial cell walls, as cells increase in population over time, protein and moisture content in colonies increase too, leading to a higher peak intensity. After $60 \mathrm{~h}$ growth, the spectral profile of S. aureus is more similar to that of B. cereus after $40 \mathrm{~h}$ and $60 \mathrm{~h}$ growth, which could have led to misclassifications for this growth period.

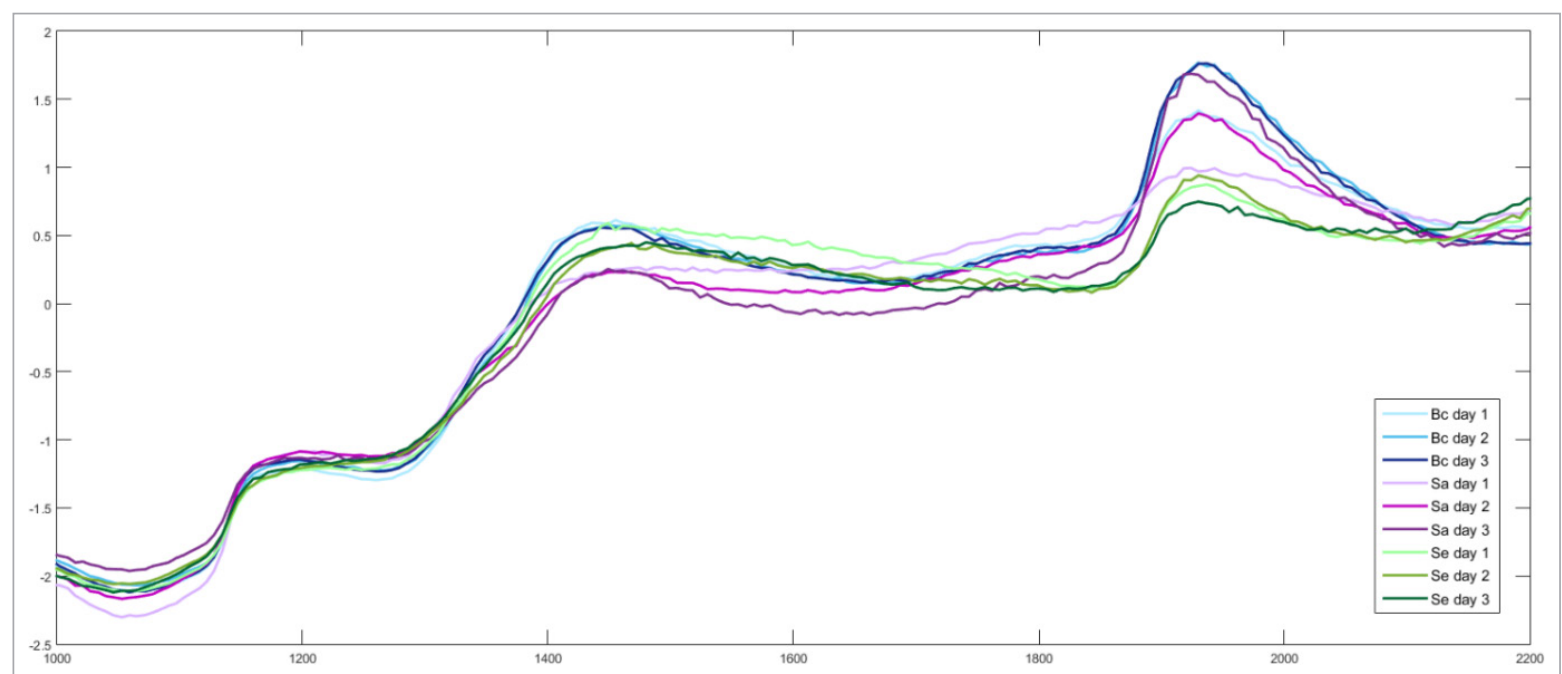

Figure 8. SNV-corrected mean spectra of group 2 [B. cereus (Bc), S. aureus (Sa) and S. epidermidis (Se)] after $20 \mathrm{~h}, 40 \mathrm{~h}$ and $60 \mathrm{~h}$ growth, with the major peak at $1937 \mathrm{~nm} \mathrm{(C=O}$, second overtone, $\mathrm{CONH} / \mathrm{O}-\mathrm{H}$ stretch + $\mathrm{O}-\mathrm{H}$ deformation, $\mathrm{H}_{2} \mathrm{O}$ ). 
Table 3. PLS-DA results of group 2 showing classification results of $20 \mathrm{~h}, 40 \mathrm{~h}$ and $60 \mathrm{~h}$ models as percentage pixels correctly predicted.

\begin{tabular}{|c|c|c|c|}
\hline & B. cereus & S. aureus & S. epidermidis \\
\hline \multicolumn{4}{|c|}{$\begin{array}{l}\text { \% Correctly predicted pixels of validation data-models built from } \\
\text { training data generated after } 20 \mathrm{~h} \text { growth }\left(R^{2}=0.80\right)\end{array}$} \\
\hline $20 \mathrm{~h}$ growth & 77.6 & 96.7 & 98.2 \\
\hline $40 \mathrm{~h}$ growth & 99.9 & 71.8 & 99.2 \\
\hline $60 \mathrm{~h}$ growth & 97.0 & 24.6 & 98.4 \\
\hline \multicolumn{4}{|c|}{$\begin{array}{l}\text { \% Correctly predicted pixels of validation data-models built from } \\
\text { training data generated after } 40 \mathrm{~h} \text { growth }\left(R^{2}=0.75\right)\end{array}$} \\
\hline $20 \mathrm{~h}$ growth & 47.4 & 97.3 & 99.3 \\
\hline $40 \mathrm{~h}$ growth & 98.4 & 95.0 & 95.2 \\
\hline $60 \mathrm{~h}$ growth & 89.6 & 61.4 & 95.1 \\
\hline \multicolumn{4}{|c|}{$\begin{array}{l}\text { \% Correctly predicted pixels of validation data-models built from } \\
\text { training data generated after } 60 \mathrm{~h} \text { growth }\left(R^{2}=0.69\right)\end{array}$} \\
\hline $20 \mathrm{~h}$ growth & 96.9 & 89.1 & 97.6 \\
\hline $40 \mathrm{~h}$ growth & 97.5 & 89.1 & 97.4 \\
\hline $60 \mathrm{~h}$ growth & 93.9 & 89.1 & 97.3 \\
\hline
\end{tabular}

For group 3 (Table 4), the $R^{2}$ for the $20 \mathrm{~h}, 40 \mathrm{~h}$ and $60 \mathrm{~h}$ models were $0.80,0.83$ and 0.83 , respectively. Model performances for this group were the best, with no prediction accuracy under $90 \%$. The highest prediction accuracies for $\mathrm{S}$. aureus was seen in the $20 \mathrm{~h}$ model, predicting the $20 \mathrm{~h}$ growth plate, with $99.8 \%$ correctly predicted pixels. For S. epidermidis, the best results were achieved with the $60 \mathrm{~h}$ model, tested on the $20 \mathrm{~h}$ growth plate, where $98.8 \%$ of pixels were correctly predicted. These two species are closely related, ${ }^{26}$ thus these results are encouraging for applications of this technique for differentiation of pathogenic and non-pathogenic species.

\section{Conclusions}

As an exploratory study, this work illustrates that the age of the colonies used to build models for pathogen differentiation proved to play a role in prediction accuracies. Of the three pre-processing methods investigated, SNV produced the best separation and clustering, and was, therefore, used as the only pre-processing method throughout data classification. Classification accuracies for most models were encouraging, regardless of the day of prediction (age of the colony). However, deviations due to different generation times could have caused misclassification of bacteria.

Granted that the most rapid classifications were desired, it was found that models built from training data generated after $60 \mathrm{~h}$ provided the overall highest prediction accuracies in each group. For this reason, we propose this period of growth (60 h) for model calibration should this method be used for differentiation of these bacteria. However, additional research is required. Future research should include different classification algorithms, such as support vector machines, however, this method requires a large number of samples (thousands) and was not included in this study. Additionally, object-wise classification of bacterial colonies using different plating methods (such as spot plates) should also be investigated as this could also improve results. In practice, spread plates would be the selected plating method used in this detection technique, since this would provide single colonies on the surface of the solid agar. Object-wise classifica- 
Table 4. PLS-DA results of group 3 showing classification results of $20 \mathrm{~h}, 40 \mathrm{~h}$ and $60 \mathrm{~h}$ models as percentage pixels correctly predicted.

\begin{tabular}{|l|c|c|}
\hline & \multicolumn{1}{|c|}{ S. aureus } & S. epidermidis \\
\hline $\begin{array}{l}\text { \% Correctly predicted pixels of validation data- } \\
\text { models built from training data generated after } 20 \mathrm{~h} \\
\left.\text { growth ( } R^{2}=0.80\right)\end{array}$ & 97.4 \\
\hline $20 \mathrm{~h}$ growth & 99.8 & 98.2 \\
\hline \begin{tabular}{l} 
40 h growth \\
\hline $60 \mathrm{~h}$ growth
\end{tabular} & 99.6 & 90.6 \\
\hline $\begin{array}{l}\text { \% Correctly predicted pixels of validation data- } \\
\text { models built training from data generated after } 40 \mathrm{~h}\end{array}$ \\
growth ( $\left.\mathrm{R}^{2}=0.83\right)$
\end{tabular}

tion models would allow entire colonies to be recognised as one bacterium and not mixtures. For example, if more than $50 \%$ of pixels in a colony were recognised as $B$. cereus, the entire colony would be classed as such, allowing for a more definitive result. This could greatly increase the accuracy of this method. Even though we employed the pixel-wise approach, our results concur with that found in the literature, i.e. culture age influences detection.

\section{Acknowledgements}

This work is based on the research supported in part by the National Research Foundation of South Africa for the grant, Unique Grant No. 94031. The authors wish to thank Professor Alvaro Viljoen, Dr Ilze Vermaak and Carmen Leonard, Tshwane University of Technology, Pretoria for use of the NIR hyperspectral imaging system and microbiology laboratory.

\section{References}

1. X. Zhao, C.-W. Lin, J. Wang and D.H. Oh, "Advances in rapid detection methods for foodborne pathogens", J. Microbiol. Biotechnol. 24, 297-312 (2014). https://doi.org/10.4014/jmb.1310.10013

2. J. Qin, K. Chao, M.S. Kim, R. Lu and T.F. Burks, "Hyperspectral and multispectral imaging for evaluating food safety and quality", J. Food Eng. 118, 157-171 (2013). https://doi.org/10.1016/j.jfoodeng.2013.04.001

3. J. Dubois, E.N. Lewis, F.S. Fry and E.M. Calvey, "Bacterial identification by near-infrared chemical imaging of food-specific cards", Food Microbiol. 22, 577-583 (2005). https://doi.org/10.1016/j. fm.2005.01.001

4. S.C. Yoon, K.C. Lawrence, J.E. Line, G.R. Siragusa, P.W. Feldner, B. Park and W.R. Windham, "Detection of Campylobacter colonies using hyperspectral imaging" Sens. Instrum. Food Qual. Saf. 4, 35-49 (2010). https://doi.org/10.1007/s11694-010-9094-0

5. T.-L. Kammies, M. Manley, P.A. Gouws and P.J. Williams, "Differentiation of foodborne bacteria using NIR hyperspectral imaging and multivariate data analysis", Appl. Microbiol. Biotechnol. 100, 93059320 (2016). https://doi.org/10.1007/s00253-0167801-4

6. S.-C. Yoon, W.R. Windham, S.R. Ladely, J.W. Heitschmidt, K.C. Lawrence, B. Park, N. Narang and W.C. Cray, "Hyperspectral imaging for differentiating colonies of non-O157 Shiga-toxin producing Escherichia coli (STEC) serogroups on spread plates of pure cultures", J. Near Infrared Spectrosc. 21, 81-95 (2013). https://doi.org/10.1255/jnirs.1043

7. D.F. Barbin, G. EIMasry, D.W. Sun, P. Allen and N. Morsy, "Non-destructive assessment of microbial contamination in porcine meat using NIR hyperspectral imaging", Innov. Food Sci. Emerg. Technol. 17, 180-191 (2013). https://doi.org/10.1016/j. ifset.2012.11.001

8. S. Yoon, K. Lawrence, G. Siragusa, J. Line, B. Park and P. Feldner, "Hyperspectral reflectance imaging for detecting a foodborne pathogen: Campylobacter", 
Trans ASABE 52, 651-662 (2009). https://doi. org/10.13031/2013.26814

9. S. Srivastava and P.S. Srivastava, "Bacteria and life processes - I Growth and multiplication", in Understanding Bacteria, $1^{\text {st }}$ Edn, Ed by S. Srivastava and P.S. Srivastava. Springer, Netherlands, pp. 97-150 (2013). https://doi.org/10.1007/978-94017-0129-7_5

10. R.E. Buchanan, "Life phases in a bacterial culture", in Micriobial Growth, Ed by P.S.S. Dawson. Dowden, Hutchinson \& Ross Inc., Stroudsburg, PA, pp. 25-41 (1974).

11. S.J. Pirt, "A kinetic study of the mode of growth of surface colonies of bacteria and fungi", J. Gen. Microbiol. 47, 181-197 (1967). https://doi. org/10.1099/00221287-47-2-181

12. J.W.T. Wimpenny, "The growth and form of bacterial colonies", Microbiology 114, 483-486 (1979).

13. H.L.C. Coutinho, B.A. Handley, H.E. Kay, L. Stevenson and J.E. Beringer, "The effect of colony age on PCR fingerprinting", Lett. Appl. Microbiol. 17, 282-284 (1993). https://doi.org/10.1111/j.1472765X.1993.tb01467.x

14. R.J. Arnold, J.A. Karty, A.D. Ellington and J.P. Reilly, "Monitoring the growth of a bacteria culture by MALDI-MS of whole cells", Anal. Chem. 71, 19901996 (1999). https://doi.org/10.1021/ac981196c

15. G. Bertani, "Studies on Iysogenesis I. The mode of phage liberation by lysogenic Escherichia coli", J. Bacteriol. 62, 293 (1951).

16. K. Esbensen and P. Geladi, "Strategy of multivariate image analysis (MIA)", Chemometr. Intell. Lab. Syst. 7, 67-86 (1989). https://doi.org/10.1016/01697439(89)80112-1

17. M. Salton, "Studies of the bacterial cell wall: IV. The composition of the cell walls of some Gram-positive and Gram-negative bacteria", Biochim. Biophys. Acta 10, 512-523 (1953). https://doi.org/10.1016/00063002(53)90296-0
18. W.W. Navarre and O. Schneewind, "Surface proteins of Gram-positive bacteria and mechanisms of their targeting to the cell wall envelope", Microbiol. Mol. Biol. Rev. 63, 174-229 (1999).

19. T.J. Beveridge, "Structures of gram-negative cell walls and their derived membrane vesicles", J. Bacteriol. 181, 4725-4733 (1999).

20. B.G. Osborne, T. Fearn and P.H. Hindle, Practical NIR Spectroscopy with Applications in Food and Beverage Analysis. Longman Scientific and Technical (1993).

21. K. Fehlhaber and G. Krüger, "The study of Salmonella Enteritidis growth kinetics using rapid automated bacterial impedance technique", J. Appl. Microbiol. 84, 945-949 (1998). https://doi.org/10.1046/j.13652672.1998.00410.x

22. I. Keren, N. Kaldalu, A. Spoering, Y. Wang and K. Lewis, "Persister cells and tolerance to antimicrobials", FEMS Microbiol. Lett. 230, 13-18 (2004). https://doi.org/10.1016/S0378-1097(03)00856-5

23. J. Collins and M. Richmond, "Rate of growth of Bacillus cereus between divisions", Microbiology 28, 15-33 (1962).

24. B. Gottenbos, D.W. Grijpma, H.C. van der Mei, J. Feijen and H.J. Busscher, "Antimicrobial effects of positively charged surfaces on adhering Gram-positive and Gram-negative bacteria", J. Antimicrob. Chemother. 48, 7-13 (2001). https://doi. org/10.1093/jac/48.1.7

25. J. Sutherland, A. Bayliss and T. Roberts, "Predictive modelling of growth of Staphylococcus aureus: the effects of temperature, $\mathrm{pH}$ and sodium chloride", Int. J. Food Microbiol. 21, 217-236 (1994). https://doi. org/10.1016/0168-1605(94)90029-9

26. A.F. Gillaspy and J.J. Landolo, "Staphylococcus", in Encyclopedia of Microbiology, Ed by M. Schaechter. Elsevier Science, San Diego, USA, pp. 293-303 (2009). https://doi.org/10.1016/B978-0123739445.00237-6 